\title{
DNA Based Identification and Phylogenetic Characterisation of Endophytic and Saprobic Fungi from Antidesma madagascariense, a Medicinal Plant in Mauritius
}

\author{
Rajesh Jeewon, ${ }^{1,2}$ Jayesh Ittoo, ${ }^{1}$ Devendra Mahadeb, ${ }^{1}$ Yasmina Jaufeerally-Fakim, ${ }^{3}$ \\ Hong-Kai Wang, ${ }^{4}$ and Ai-Rong Liu ${ }^{2}$ \\ ${ }^{1}$ Departmental of Health Sciences, Faculty of Science, University of Mauritius, Reduit, Mauritius \\ ${ }^{2}$ College of Forestry, Henan University of Science and Technology, Luoyang 471003, China \\ ${ }^{3}$ Faculty of Agriculture, University of Mauritius, Reduit, Mauritius \\ ${ }^{4}$ Department of Plant Protection, College of Agriculture \& Biotechnology, Zhejiang University, Hangzhou 310029, China
}

Correspondence should be addressed to Rajesh Jeewon; r.jeewon@uom.ac.mu

Received 28 February 2013; Accepted 3 May 2013

Academic Editor: Praveen Rao Juvvadi

Copyright (C) 2013 Rajesh Jeewon et al. This is an open access article distributed under the Creative Commons Attribution License, which permits unrestricted use, distribution, and reproduction in any medium, provided the original work is properly cited.

\begin{abstract}
Endophytes are fungi associated with plants without causing symptoms, and they are quite diverse and have enormous potential for production of important secondary metabolites for the pharmaceutical industry. In this study, we report for the first time fungi (both endophytes and saprobes) from Antidesma madagascariense, a medicinal plant in Mauritius, in view of identifying potential candidates for screening of fungi for pharmaceutical importance. In addition the phylogenetic placement of fungi recovered from leaves samples was investigated based on rDNA sequence analysis. Most commonly isolated fungi were related to Aspergillus, Guignardia, Fusarium, Penicillium, Pestalotiopsis, and Trichoderma. Phylogenetic analyses revealed that fungi recovered belong to 5 different fungal lineages (Hypocreaceae, Trichocomaceae, Nectriaceae, Xylariaceae, and Botryosphaeriaceae). DNA data from the ITS regions were reliable in classification of all recovered isolates up to genus level, but identification to an exact species name was not possible at this stage. Despite criticisms pertaining to the use of ITS sequence data in molecular systematics, our approach here provides an opportunity to justify the reliability of ITS sequence data for possible identification and discovering of evolutionary scenarios among isolates that do not sporulate under cultural conditions.
\end{abstract}

\section{Introduction}

Endophytes are fungi that inhabit internal tissues or organs without causing obvious symptoms of tissue damage and have been commonly isolated from many plants [1], and a number of them apparently change their ecological strategies and adopt a saprotrophic lifestyle whenever plants senescence [2]. Although endophytes have wide host ranges, a number of them might be host specific and have been well studied, especially with respect to harvesting their biological properties and as a reservoir for novel and natural bioactive compounds [3].

There has been an increasing interest in isolation of fungal endophytes from plants from many tropical regions. However, research in this aspect in Mauritius is rather scanty.
There is only one published paper by Toofanee and Dulymamode [4] who reported that Pestalotiopsis was isolated as the most dominant endophytic fungus from the leaves of Cordemoya integrifolia. In this study, an endemic medicinal plant of Mauritius, Antidesma madagascariense Lam. (Euphorbiaceae), was selected for endophytic screening as it has been well documented that this plant possesses pharmacologically active compounds and phytochemicals that have got antioxidant, antibacterial, and antifungal activities $[5,6]$.

Traditionally, identification of endophytes relied heavily on morphological and cultural characterization of isolates. However due to the intricacies of morphological characters, many endophytes have never been properly identified, even up to a familial level. Another major drawback of cultural studies is that many endophytes exist as mycelial (vegetative) 
propagules, never produce spores, are left unaccountable, and therefore provide bias data regarding fungal diversity. The same applies for many saprobes from dead plant substrates. The implications of PCR based methodologies have altered our views about the way we used to think about fungal endophytic and saprobic diversity. To date, DNA sequencing coupled with phylogenetic analyses has paved the way for reliable identification as well as classification of a number of unidentified endophytes and saprobes within other known fungal lineages. Given that all recovered fungal samples failed to produce spores to enable identification through microscopy, DNA sequences from the fast-evolving ribosomal ITS (and conserved region of the $5.8 \mathrm{~S}$ ) regions were analysed to evaluate the identity, diversity, classification, and evolutionary relationships of a number of endophytic fungal isolates as well as saprobes. In particular the objectives are to

(i) identify fungal endophyte and saprobes isolated from Antidesma madagascariense based DNA sequence analysis of the ITS regions of the ribosomal gene and

(ii) investigate the evolutionary relationships and phylogenetic classification of unidentified endophytes and saprobes within known fungal lineages.

\section{Materials and Methods}

2.1. Plant Species and Fungal Sources. Antidesma madagascariense, a local plant, was selected for this study because of its pharmacological importance. Fungal cultures used in this study were isolated as saprotrophs and endophytes from living and dead leaves and twigs of Antidesma madagascariense. Healthy mature living leaves as well as dead ones, which were randomly collected, were treated for endophytic and saprophytes isolation as described by Promputtha et al. [7]. Cultures on media such as potato dextrose agar and corn meal agar obtained were examined periodically and identified when isolates start to produce sporulating type-like structures. Under most circumstances, only the anamorphic stage of the fungi was observed under the microscope (with only hyphal elements and no spores). The remaining isolates which failed to sporulate were treated as mycelia sterilia and classified into morphospecies based on cultural characteristics [7]. Fungal cultures were grown on PDA plates for 5-20 days, and genomic DNA was extracted from fresh mycelium using a protocol as outlined by Jeewon et al. [8].

2.2. PCR Amplification and DNA Sequencing and Phylogenetic Data Analysis. Primer pair ITS4 and ITS5 as designed by White et al. [9] was used to amplify the 5.8S gene and flanking ITS1 and ITS2 regions. Amplification was performed in a $50 \mu \mathrm{L}$ reaction volume containing $5 \mu \mathrm{L}$ of $10 \mathrm{X} \mathrm{Mg}$ free PCR buffer, $3 \mu \mathrm{L}$ of $25 \mathrm{mM} \mathrm{MgCl}, 4 \mu \mathrm{L}$ of $2.5 \mathrm{mM}$ deoxyribonucleotide triphosphates (dNTPs), $1.5 \mu \mathrm{L}$ of $10 \mu \mathrm{M}$ primers (ITS4 and ITS5), and $3 \mu \mathrm{L}$ of DNA template, $0.3 \mu \mathrm{L}$ of 2.5 units of Taq DNA polymerase. The thermal cycle consisted of 3-minute initial denaturation at $95^{\circ} \mathrm{C}$, followed by 30 cycles of 1-minute denaturation at $95^{\circ} \mathrm{C}, 50$-second primer annealing at $52^{\circ} \mathrm{C}, 1$-minute extension at $72^{\circ} \mathrm{C}$, and a final 10 minute extension at $72^{\circ} \mathrm{C}$. The PCR products were examined by electrophoresis in $1 \%(w / v)$ agarose gel with ethidium bromide $(10 \mathrm{mg} / \mathrm{mL})$ and checked for size and purity. Purified PCR products were then directly sequenced in an automated sequencer at Indaba, South Africa. Primer pair ITS4 and ITS5 was used in the sequencing reaction.

The consensus sequences obtained from both primers obtained were first edited and subject to BLAST searches to assign putative identity, designation of operational taxonomic units based on sequence similarity measures, and phylogenetic inference. They were then aligned with other similar sequences downloaded from GenBank using ClustalX [10] and BioEdit [11] and MEGA program [12]. Alignments were manually edited where necessary, but this was seldom necessary. Sequences obtained were split into different datasets in order to access phylogenetic relationships at the familial and species level. Phylogenetic analyses for maximum parsimony (MP), maximum likelihood (ML) and neighbour joining (NJ) analyses were performed by using PAUP 4.0 [13] and with MEGA [12] as well. Branch support of the trees resulting from maximum parsimony (MP) was assessed by bootstrapping (analysis was performed with 1000 replications using the heuristic search option to estimate the reliability of inferred monophyletic groups). Other further details on phylogenetic analyses are discussed elsewhere in Jeewon et al. [8, 14]. Under some circumstances, a few regions of the ITS1 and ITS2 have to be excluded from the analyses as they were slightly too variable. Sequences employed in the molecular datasets ranged from 550 to $650 \mathrm{bp}$ in length prior to the elimination of ambiguous or unalignable data, especially at the beginning and the end (not shown). To access the taxonomic placement of the isolates at the familial, genetic, or species level, sequences were analysed in 5 different datasets given that, based on preliminary analyses, they were found to belong to 5 different familial lineages. Sequences have been submitted to GenBank.

\section{Results and Discussion}

Table 1 shows the number of different endophytes and saprobes isolated from plant tissues as well as their most similar species based sequence similarity arising from blast search results.

3.1. Phylogenetics of Isolates Related to the Hypocreaceae. Most of the fungi recovered in this study belong to the family Hypocreaceae. A dataset of 43 taxa with Cordyceps as outgroup was analysed under different criteria. Parsimony analysis of this dataset produced the 63 most parsimonious trees of 332 steps in length (L) while ML analyses reveal that there are 3 endophytes and 9 saprobes that are related to the Hypocreaceae (Figure 1). Both trees were congruent in topology, and well-supported lineages within this group (supported in $>70 \%$ of 1000 bootstrap replicates) included members from Clade A, which consists of Endophyte R25 and Saprobes S10a, S10b, S2, S19, and S15. Our phylogeny confirms a close relationship of those species to the members of the genus Trichoderma, which is in the family Hypocreaceae, but it does not clearly resolve the identity of those species to any particular Trichoderma species, despite a very close similarity 
TABLE 1: Fungal isolates recovered from leaves samples of Antidesma madagascariense and the length of their ITS sequences.

\begin{tabular}{|c|c|c|c|}
\hline & GenBank accession numbers & Query coverage (\%) & Max. identity (\%) \\
\hline \multicolumn{4}{|c|}{ Endophytes and their similar sequences from Genbank based on blast search } \\
\hline \multicolumn{4}{|l|}{ Endophyte R1: length 458 nucleotides } \\
\hline Fusarium oxysporum strain $\mathrm{FuO} 139$ & KC196121 & 100 & 100 \\
\hline Fusarium oxysporum $f$. sp. ciceris isolate Foc- 82108 & KC478162 & 100 & 100 \\
\hline \multicolumn{4}{|l|}{ Endophyte R2: length 456 nucleotides } \\
\hline Pestalotiopsis microspora isolate HF12440 & JQ863222 & 100 & 100 \\
\hline Pestalotiopsis mangiferae strain E1392 & JX997752 & 99 & 100 \\
\hline \multicolumn{4}{|l|}{ Endophyte R3: length 483 nucleotides } \\
\hline Fusarium oxysporum CMT6 & JQ754006 & 100 & 100 \\
\hline Fusarium oxysporum cepae & HQ658969 & 100 & 100 \\
\hline \multicolumn{4}{|l|}{ Endophyte R6: length 491 nucleotides } \\
\hline Neofusicoccum parvum isolate Lanmei4-14 & JX096635 & 100 & 99 \\
\hline Neofusicoccum parvum isolate Lijiang23 & JX096633 & 100 & 99 \\
\hline \multicolumn{4}{|l|}{ Endophyte R7: length 508 nucleotides } \\
\hline Guignardia sp. CYP7 & KC145173 & 100 & 100 \\
\hline Guignardia mangiferae strain ZJUCC200999 & JN791608 & 100 & 100 \\
\hline \multicolumn{4}{|l|}{ Endophyte R9: length 542 nucleotides } \\
\hline Cyphomyrmex muelleri fungal symbiont NJM-2012 & JQ617621 & 100 & 99 \\
\hline Acremonium polychromum strain: T6713-22-1a & AB540547 & 100 & 99 \\
\hline \multicolumn{4}{|l|}{ Endophyte R11: length 526 nucleotides } \\
\hline Cyphomyrmex muelleri fungal symbiont & JQ617621 & 100 & 99 \\
\hline Acremonium polychromum collection UTHSC:08-1028 & FN706548 & 100 & 99 \\
\hline \multicolumn{4}{|l|}{ Endophyte R20: length 524 nucleotides } \\
\hline Fusarium oxysporum & JF776163 & 99 & 100 \\
\hline Fusarium oxysporum cucumerinum ATCC 16416 & DQ452450 & 99 & 100 \\
\hline \multicolumn{4}{|l|}{ Endophyte R21: length 561 nucleotides } \\
\hline Guignardia sp. SEGA49 & JN607105 & 100 & 100 \\
\hline Guignardia mangiferae strain ZJUCC200999 & JN791608 & 100 & 100 \\
\hline \multicolumn{4}{|l|}{ Endophyte R22: length 491 nucleotides } \\
\hline Fusarium oxysporum strain DB0612101 & HQ682196 & 100 & 100 \\
\hline Fusarium sp. EMA-2011 & JF429684 & 100 & 99 \\
\hline \multicolumn{4}{|l|}{ Endophyte R25: length 569 nucleotides } \\
\hline Fungal sp. ARIZ B089 & FJ612909 & 100 & 99 \\
\hline Trichoderma sp. & AY514867 & 100 & 99 \\
\hline \multicolumn{4}{|l|}{ Endophyte R26: length 484 nucleotides } \\
\hline Fungal endophyte strain MX482 & JX155942 & 100 & 99 \\
\hline Penicillium westlingii & AF033423 & 100 & 99 \\
\hline \multicolumn{4}{|l|}{ Endophyte R28: length 312 nucleotides } \\
\hline Penicillium sp. & HQ316567 & 100 & 98 \\
\hline Penicillium griseofulvum & HE805121 & 99 & 98 \\
\hline \multicolumn{4}{|c|}{ Saprophytes } \\
\hline \multicolumn{4}{|l|}{ Saprophyte S1: length 508 nucleotides } \\
\hline Trichoderma koningiopsis isolate UFSM-Tr1s & KC155356 & 100 & 100 \\
\hline Trichoderma gamsii strain CS11784 & JX406518 & 100 & 100 \\
\hline \multicolumn{4}{|l|}{ Saprophyte S2: length 553 nucleotides } \\
\hline Hypocrea lixii isolate B1a0034EM2CC39 & JQ411358 & 100 & 99 \\
\hline Fungal endophyte strain MS429 & JX155901 & 100 & 99 \\
\hline
\end{tabular}


TABle 1: Continued.

\begin{tabular}{|c|c|c|c|}
\hline & GenBank accession numbers & Query coverage (\%) & Max. identity (\%) \\
\hline \multicolumn{4}{|l|}{ Saprophyte S3: length 537 nucleotides } \\
\hline Trichoderma koningiopsis strain PROF4 & JX069202 & 100 & 99 \\
\hline Trichoderma gamsii strain CQBN3005 & JQ040342 & 100 & 99 \\
\hline \multicolumn{4}{|l|}{ Saprophyte S4: length nucleotides } \\
\hline Aspergillus versicolor strain dl-29 & JX401544 & 100 & 99 \\
\hline Aspergillus versicolor culture-collection UOA/HCPFGRC & KC253963 & 100 & 99 \\
\hline \multicolumn{4}{|l|}{ Saprophyte S8: length 538 nucleotides } \\
\hline Trichoderma gamsii strain TU Graz 8TSM5 & EU871026 & 100 & 99 \\
\hline Trichoderma koningiopsis strain NAN11 & JX069207 & 100 & 99 \\
\hline \multicolumn{4}{|l|}{ Saprophyte S9: length 566 nucleotides } \\
\hline Aspergillus niger strain E-000535890 & JN545800 & 99 & 99 \\
\hline Aspergillus niger strain KAML02 & KC119204 & 99 & 99 \\
\hline \multicolumn{4}{|l|}{ Saprophyte S10A: length 543 nucleotides } \\
\hline Hypocrea lixii strain BRFM 1285 & JX082390 & 100 & 99 \\
\hline Hypocrea lixii isolate Bla0034EM2CC39 & JQ411358 & 100 & 99 \\
\hline \multicolumn{4}{|l|}{ Saprophyte S10B: length 555 nucleotides } \\
\hline Trichoderma album strain APT08 & JF304318 & 99 & 99 \\
\hline Fungal endophyte strain MS153 & JX155866 & 99 & 99 \\
\hline \multicolumn{4}{|l|}{ Saprophyte S11: length 545 nucleotides } \\
\hline Trichoderma koningiopsis & JX238474 & 99 & 99 \\
\hline Trichoderma koningiopsis strain SHSJ8001 & JQ040369 & 99 & 99 \\
\hline \multicolumn{4}{|l|}{ Saprophyte S15: length 605 nucleotides } \\
\hline Hypocrea lixii isolate PCO.89 & HQ248196 & 100 & 99 \\
\hline Hypocrea lixii strain Tri102 & HQ229942 & 100 & 99 \\
\hline \multicolumn{4}{|l|}{ Saprophyte S17: length 506 nucleotides } \\
\hline Fusarium sp. VegaE3-61 & EF687913 & 98 & 98 \\
\hline Fusarium sp. IBL 031571 & DQ682580 & 99 & 99 \\
\hline \multicolumn{4}{|l|}{ Saprophyte S19: length 575 nucleotides } \\
\hline Fungal endophyte strain MS429 & JX155901 & 98 & 99 \\
\hline Fungal sp. ARIZ B426 & FJ613029 & 98 & 99 \\
\hline
\end{tabular}

in DNA sequence and phylogenetic affiliation to T. album. There is quite weak support to suggest that those endophytes or saprobes could be T. album. Nevertheless, even if proper identification up to a species level has not been possible with the ITS sequences, it is confirmed that these species belong to the genus Trichoderma as they cluster with high bootstrap (BT) support (99\%) with other Hypocrea and Trichoderma species. A similar scenario is observed with Saprobes S11, S8, and $\mathrm{S} 1$ (Clade B, which bears 74\% BT support). In particular it is noted that S11, S8, and S1 are related to Trichoderma gamsii while S3 is nested in between and shares close affinities to Hypocrea viridescens and Trichoderma viride.

Phylogenetic association between our saprobes and Trichoderma is not surprising as Trichoderma species are ubiquitous and frequently dominant components of the soil microflora in widely varying habitats and even from dead plant tissues $[15,16]$. However, it must also be mentioned that Trichoderma is also capable of more intimate associations with plant tissues and can be opportunistic pathogens as well [17]. Recent studies have also revealed that many plant species do harbor Trichoderma as endophytes [18], and this is in agreement with our findings in here. Even one of the ingroups, Fungal sp. ARIZ (bearing Genbank Accession no. FJ613088) used in our dataset, is an endophyte isolated from seeds of Cecropia insignis [19]. It is observed that Trichoderma and Hypocrea also cluster together and share the same ancestors despite morphological dissimilarities because they are anamorphs (asexual manifestation) and teleomorphs (sexual manifestation) of each other [20].

Another interesting finding of the phylogenetic study herein shows an intimate association between endophyte and saprobe (e.g., Endophyte R25 and Saprobe S2) with respect to their ecological roles. It is highly possible that based on sequence identity and close phylogenetic connection Endophyte R25 can change its ecological strategies and adopt a saprotrophic lifestyle (e.g., Saprobe S2) as it has been 


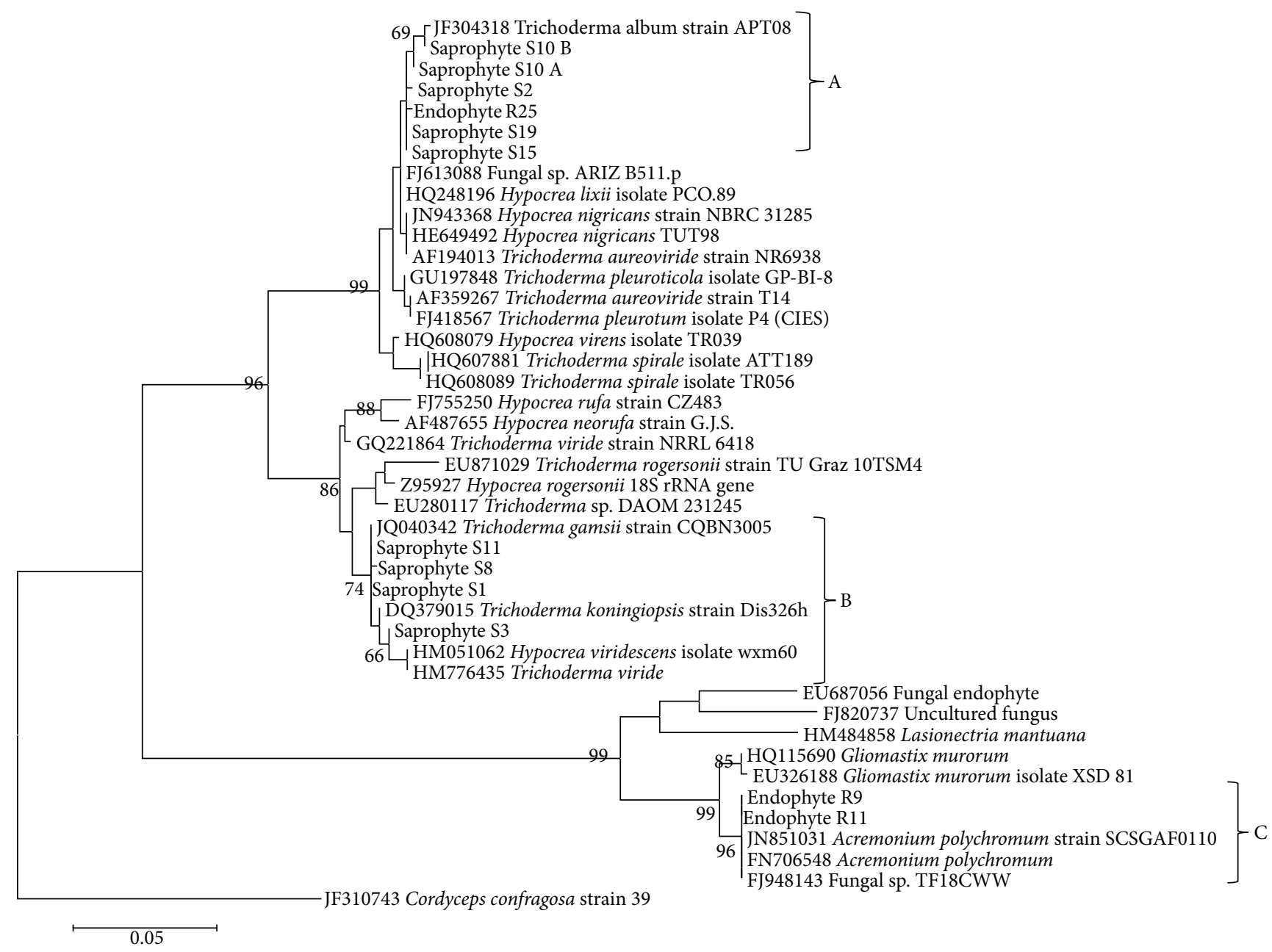

FIGURE 1: Phylogenetic relationships of recovered endophytes and saprobes with selected anamorphs and teleomorphs of Hypocreaceae genera based on ITS rDNA sequences. The phylogram represents a maximum likelihood tree based on analyses of 43 taxa under the HKY model. The tree was rooted with Cordyceps confragosa as outgroup. Bootstrap values higher than or equal to $50 \%$ (1000 replicates) are shown at each branches.

postulated that fungal endophytes become saprotrophs after the onset of senescence of host tissue, and recent phylogenies have provided circumstantial evidence to support this phenomenon [7]. However, to validate such an assumption, a proper evaluation of production of similar enzymes especially those in decomposition is necessary. A 96\% BT support for Endophyte, R9 and R11 in Clade C clearly shows that they are related to Acremonium and therefore should be retained in this genus. Acremonium is generally considered to be ubiquitous fungi but has also been isolated as clavicipitaceous grass and insects endophytes [21, 22].

3.2. Taxonomic Placement of Endophytic and Saprobic Isolates Related to the Trichocomaceae and Nectriaceae. ML Phylogeny obtained from the ITS dataset with 23 taxa and 528 characters confirms that Saprobes S9 and S4 are Aspergillus species (Figure 2). In particular S9 clusters with $A$. niger with $75 \%$ BT support and is sister taxon to A. tubingensis (with $80 \%$ BT support) whereas $\mathrm{S} 4$ is basal to A. creber and A. versicolor with $93 \%$ BT support. Aspergillus is a well-known saprotroph and can easily be recovered from leaves [23]. Taxonomic affinities and classification of Aspergillus are quite controversial and complex due to morphological plasticity among different strains at the intraspecies level. No extensive analyses have been dealt with in this study, but the already published phylogenies by Prabakaran et al. [23] clearly demonstrate that S4 should belong to the section Versicolores clade and within the A. sydowii subclade. On the other hand, S9 shares a close phylogenetic association with $A$. niger. The latter is a complex taxonomic group of taxa that constitutes eight morphologically indistinguishable taxa: A. niger, Aspergillus tubingensis, Aspergillus acidus, Aspergillus brasiliensis, Aspergillus costaricaensis, Aspergillus lacticoffeatus, Aspergillus piperis, and Aspergillus vadensis [24]. It could be that S9 is anyone of those strains, but the possibility of discovering a lot of cryptic species (whether endophytes or saprobes) within this group cannot be overlooked as showed by A. awamori [24].

Penicillium species also exists as endophytes from many plant species $[23,25]$ and results here in accommodate two Endophytes R26 and R28 to the genus Penicillium with 100\% 


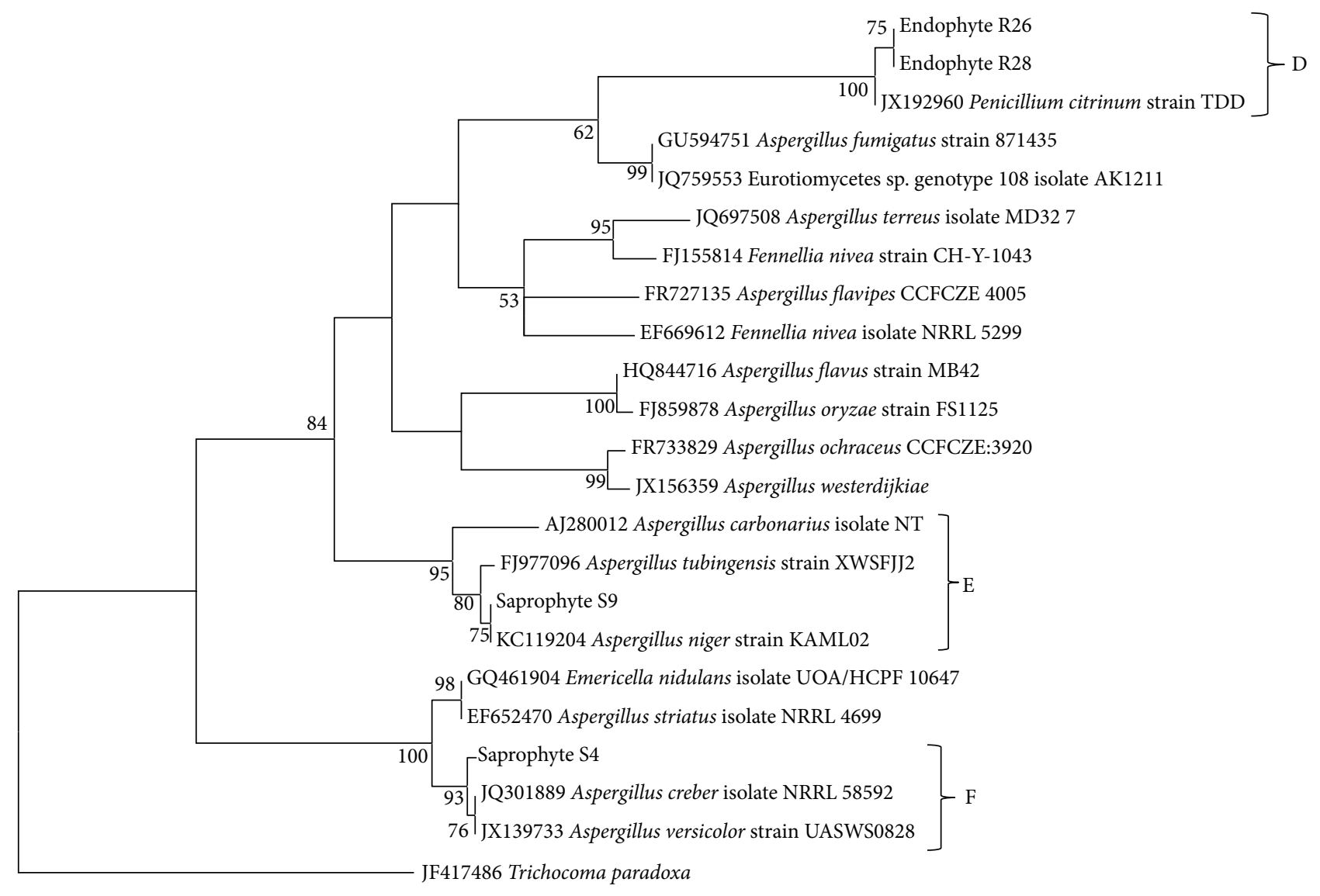

$\longmapsto 0.02$

FIGURE 2: Phylogeny obtained from maximum likelihood analysis based on ITS sequence dataset with 23 taxa (Trichocomaceae) and 528 sites. Outgroup is Trichocoma paradoxa. Bootstrap values higher than or equal to 50\% (1000 replicates) are shown at each branches.

11 BT support. Given their relatedness to $P$. citrinium and following rDNA based phylogeny obtained by Houbraken et al. [26], it is can be expected that those two endophytes will belong to the Penicillium section Citrina. It is also worth pointing out that $P$. citrinium isolated from marine environments has got the possibility to produce important secondary metabolites (those of citrinin derivatives) that exhibited significant cytotoxic activity against HL-60 cells [27]. This possibly highlights the importance of identifying unknown endophytes based on DNA sequence data to ease selection and screening of potential fungal candidates for bioactive potential in the future.

Analyses of sequence data with 19 taxa and 508 characters yielded an ML tree of $\log -1550.3$ and depicts that 4 endophytes (R1, R3, R20, and R22) and Saprobe S17 group together with other Fusarium species with excellent statistical support (100\% and 94\% BT support, resp.; Figure 3). Apart from Alternaria, Phomopsis, and Colletotrichum, Fusarium has also been widely isolated as endophytes or even saprobes $[7,16,23]$. Two of the closest relatives of our endophytes and saprobes in the Nectriaceae clade are actually pathogenic fungi $[28,29]$. This points out to the relative significance of those organisms as potential pathogenic species depending upon the environment and their lifestyle.
3.3. Relationships of Endophytic Mycelia Sterilia R2 and R6, R7, and R21 to Pestalotiopsis and Botryosphaeriaceae, Respectively. Blast search results showed that R2 is a unitunicate ascomycete and had high sequence similarities (>95\%) with other species of Pestalotiopsis. DNA sequence analyses confirm that endophyte R2 is a species of Pestalotiopsis (Figure 4). The latter is frequently isolated as endophytes [30,31] and has been shown to be promising candidates for biotechnological purposes. It would be quite difficult, however, to ascertain to which species our endophyte is mostly related to as taxonomic circumscription within the genus itself is still obscure as shown by Jeewon et al. [8, 32-34]. Nevertheless, if cultures of this endophyte are induced to sporulate, they should produce conidia that are usually 5-celled, with 3 brown median cells and hyaline end cells and with two or more apical appendages arising from the apical cell [35].

Comparison of sequences of the ITS regions showed that Endophytes R7 and R21 had high similarities with Guignardia and its anamorphic Phyllosticta species (96100\%) while R6 was similar to Neofusicoccum and its teleomorphic Botryosphaeria counterpart. ML phylogenies revealed that R21 and R7 constitute a strong and highly supported monophyletic lineage with Guignardia mangiferae, Phyllosticta, and a few uncultured species (Figure 5; Clade J). 


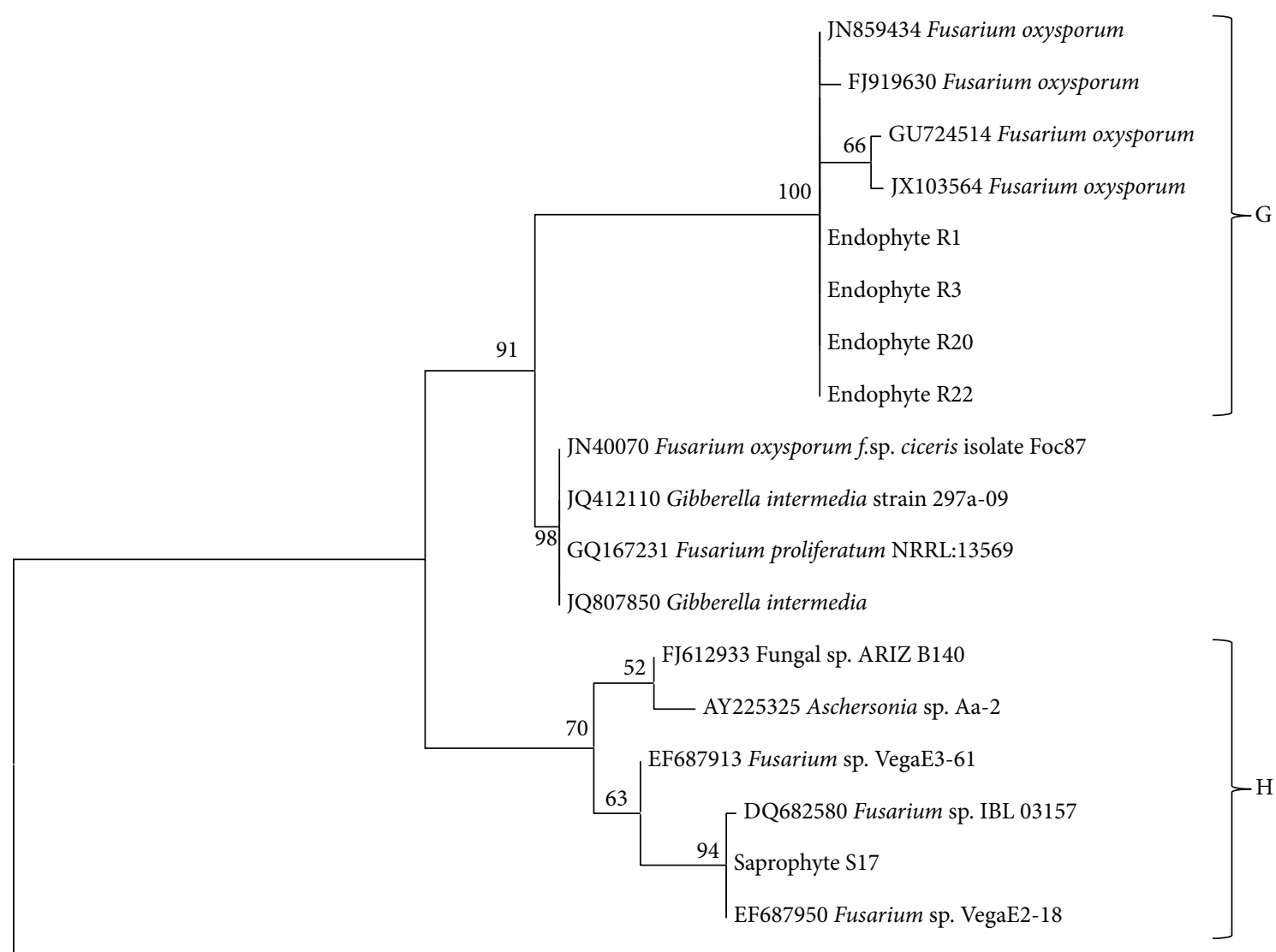

GQ203544 Hypocrea lixii strain SWFC8926

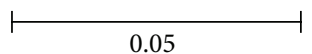

FIGURE 3: Maximum likelihood tree (log-1550.31) of ITS sequences analysis of 19 taxa to show the relationships of 4 and 1 endophytic and saprobic isolates, respectively, among the family Nectriaceae. Outgroup is Hypocrea Lixii. Bootstrap values higher than or equal to $50 \%$ (1000 replicates) are shown at each branches.

Phyllosticta species have often been reported as endophytes, plant pathogens, or saprobes (e.g., [36-38]). Based on ITS sequence data, Pandey et al. [39] have shown that Phyllosticta can be recovered as an endophyte from foliar leaves and that it has its sexual counterpart within Guignardia. Similarly, Crous et al. [40] have also demonstrated that species of Phyllosticta represent anamorphs of Guignardia (Botryosphaeriaceae). Based on our current cultural studies and cultural characteristics, it is quite difficult to suggest whether R7 or R21 is exhibiting its anamorphic or teleomorphic stage as no spores were observed. Even in current rDNA phylogenies in here, it is seen that these endophytes are related to other fungal endophytes (AY601899; EF419973) which have not been identified up to species level but classified with certainty within Guignardia/Phyllosticta as documented in other studies as well $[41,42]$.

ML phylogenies generated in this study also indicate that there is a close phylogenetic association between Endophyte R6 with Neofusicoccum and Botryosphaeria in a strong monophyletic clade (Figure 5; Clade K), and such association between endophytes and those bitunicates fungi has already been well established [7]. There have been debates on whether endophytes can be pathogens and cause harm to plants. Phylogenies herein depict a close affiliation between R6 and other Neofusicoccum and Botryosphaeria species which have been reported to cause diseases in plants [43], and therefore the possibility of specific endophytes becoming pathogenic through a shift in their ecological roles, host colonization patterns, or mechanism of transmission between host generations should not be overlooked.

\section{Conclusion}

Our findings contribute to the understanding and diversity of the different groups of endophytic and saprobic fungi associated with an important endemic plant which have been shown to possess compounds of pharmaceutical properties. Although the number of isolates obtained is small as compared to other endophytic studies, it does provide a broad view of the different groups of fungi associated with leaves of Antidesma madagascariense, and most questions pertaining to their identity and evolutionary relationships are resolved through rDNA sequence analyses. 


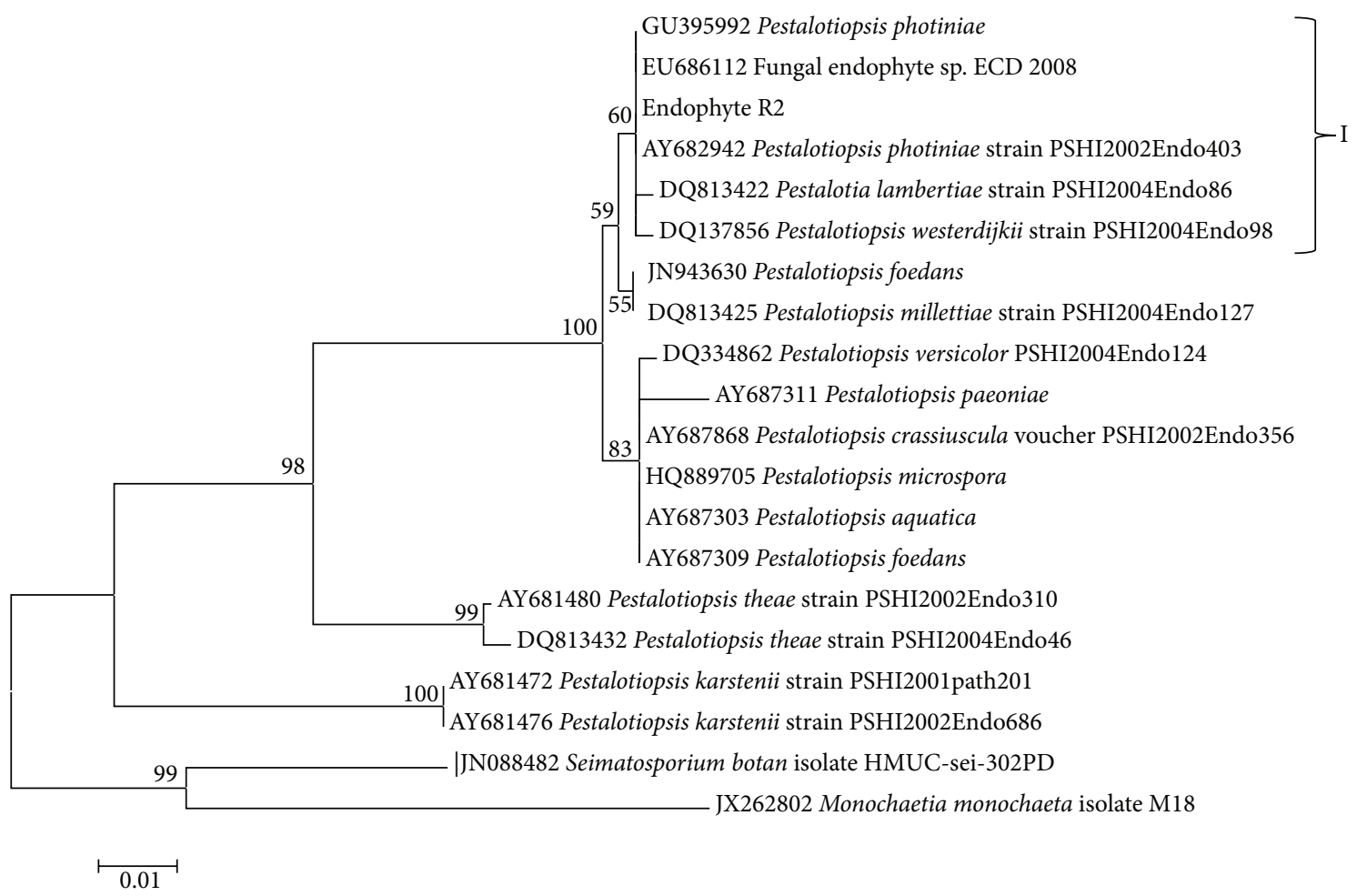

FIGURE 4: Maximum likelihood tree generated from ITS sequences of 20 taxa showing the relationships of Endophytes R2 with reference taxa. The tree was rooted with Seimatosporium and Monochaetia. Bootstrap values higher than or equal to $50 \%$ (1000 replicates) are shown at each branches.

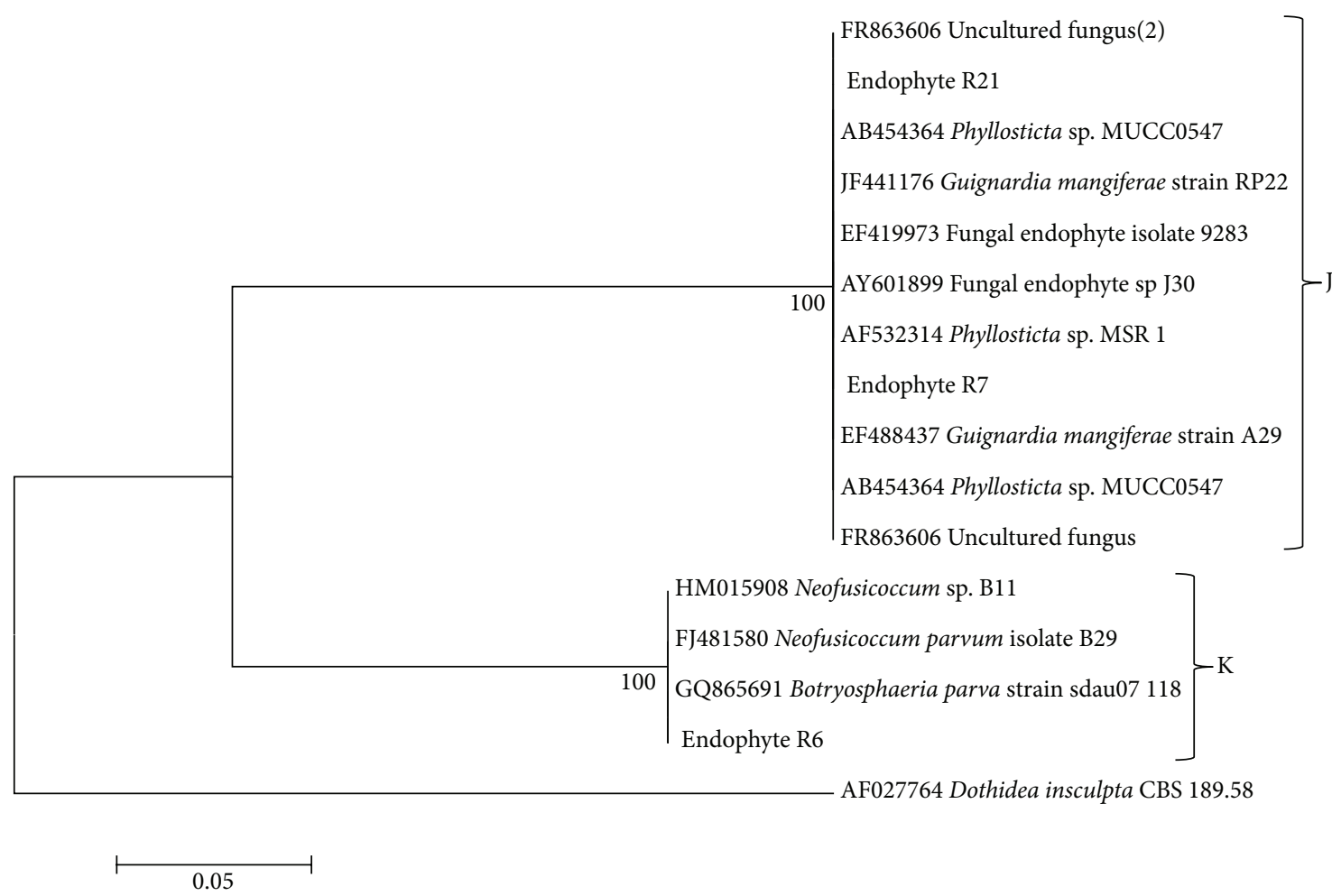

FIGURE 5: Phylogenetic relationships of recovered endophytes with selected anamorphs and teleomorphs of Botryosphaericaeae genera based on ITS rDNA sequences. The phylogram represents a maximum likelihood tree (log -1637.06) and rooted with Dothidea insculpta as outgroup. Bootstrap values higher than or equal to $50 \%$ (1000 replicates) are shown at each branches. 
The impact of molecular systematics on fungal classification and identification has been profound. Indeed, phylogenies based on the sequence of ribosomal RNA genes contributed significantly to the diversity of unknown saprotrophs and endophytes. There have been concerns about the utility of the ITS regions of the rDNA as a phylogenetic marker in molecular systematics studies. Our studies here demonstrate ultimately that, despite all intricacies of the ribosomal DNA gene, it is still quite reliable in assessing generic placement of many unidentified fungal species. However, we note that it may or may not be informative phylogenetically to accurately identify a species and resolve intraspecific differences, unless broader sampling is used.

Another important conclusion from our molecular analysis is that most species isolated comprise mostly Pestalotiopsis, Fusarium, Penicillium, Aspergillus, and Trichoderma. Questions still unanswered are whether our current or conventional methods (especially use of artificial culture) that have been used to recover endophytic or saprotrophs from plant samples do not favour the recovery of only fast growing fungi or only those that grow in those specific media.

Should we target and combine other methods and undertake a polyphasic approach to know "where are the missing endophytes?"

\section{Acknowledgments}

The Department of Health Sciences, Faculty of Science, and the Faculty of Agriculture, University of Mauritius, are also acknowledged for support. Special thanks are due to Oliver for his technical assistance. Dr. F. Mahomoodally is thanked for his help with plants. This work was supported by the National Natural Science Foundation of China Grants (nos. 30700002, 30270015, 30470004, 39899400, 30370006, 30230020, 40971156, and 30930005), the Knowledge Innovation Program of the Chinese Academy of Sciences (nos. KSCX2-YW-G-068 and KSCX2-YW-Z-0935), and the National Science Foundation for Postdoctoral Scientists of China (Grant no. 20070411191).

\section{References}

[1] A. H. Aly, A. Debbab, J. Kjer, and P. Proksch, "Fungal endophytes from higher plants: a prolific source of phytochemicals and other bioactive natural products," Fungal Diversity, vol. 41, pp. 1-16, 2010.

[2] I. Promputtha, S. Lumyong, V. Dhanasekaran, E. H. C. McKenzie, K. D. Hyde, and R. Jeewon, "A phylogenetic evaluation of whether endophytes become saprotrophs at host senescence," Microbial Ecology, vol. 53, no. 4, pp. 579-590, 2007.

[3] T. S. Suryanarayanan, N. Thirunavukkarasu, M. Govindarajulu, and V. Gopalan, "Fungal endophytes: an untapped source of biocatalysts," Fungal Diversity, vol. 54, pp. 19-30, 2012.

[4] S. B. Toofanee and R. Dulymamode, "Fungal endophytes associated with Cordemoya integrifolia," Fungal Diversity, vol. 11, pp. 169-175, 2002.

[5] F. B. Narod, A. Gurib-Fakim, and A. H. Subratty, "Biological investigations into Antidesma madagascariense Lam. (Euphorbiaceae), Faujasiopsis flexuosa (Lam.) C. Jeffrey (Asteraceae),
Toddalia asiatica (L.) Lam. and Vepris lanceolata (Lam.) G. Don (Rutaceae)," Journal of Cell and Molecular Biology, vol. 3, pp. 1521, 2004.

[6] F. M. Mahomoodally, A. H. Subratty, A. Gurib-Fakim, and M. I. Choudhary, "Antioxidant, antiglycation and cytotoxicity evaluation of selected medicinal plants of the Mascarene Islands," BMC Complement Alternative Medicine, vol. 12, article 165, 2012.

[7] I. Promputtha, R. Jeewon, S. Lumyong, E. H. C. McKenzie, and K. D. Hyde, "Ribosomal DNA fingerprinting in the identification of non sporulating endophytes from Magnolia lilifera (Magnoliaceae)," Fungal Diversity, vol. 20, pp. 167-186, 2005.

[8] R. Jeewon, E. C. Y. Liew, and K. D. Hyde, "Phylogenetic evaluation of species nomenclature of Pestalotiopsis in relation to host association," Fungal Diversity, vol. 17, pp. 39-55, 2004.

[9] T. J. White, T. D. Bruns, S. Lee, and J. W. Taylor, "Amplification and direct sequencing of fungal ribosomal RNA genes for phylogenetics," in PCR ProTocols: A Guide To Methods and Applications, M. A. Innis, D. H. Gelfand, J. S. Sninsky, and T. J. White, Eds., pp. 315-322, Academic Press, New York, NY, USA, 1990.

[10] J. D. Thompson, T. J. Gibson, F. Plewniak, F. Jeanmougin, and D. G. Higgins, "The CLUSTAL X windows interface: flexible strategies for multiple sequence alignment aided by quality analysis tools," Nucleic Acids Research, vol. 25, no. 24, pp. 48764882, 1997.

[11] T. A. Hall, "BioEdit: a user-friendly biological sequence alignment, and analysis program for Windows 95/98/NT," Nucleic Acids Symposium Series, vol. 41, pp. 95-98, 1999.

[12] K. Tamura, D. Peterson, N. Peterson, G. Stecher, M. Nei, and S. Kumar, "MEGA5: molecular evolutionary genetics analysis using maximum likelihood, evolutionary distance, and maximum parsimony methods," Molecular Biology and Evolution, vol. 28, no. 10, pp. 2731-2739, 2011.

[13] D. L. Swofford, "PAUP*. Phylogenetis Analysis Using Parsimony (*and Other Methods), version 4.0b10," Sinauer Associates, Sunderland, Mass, USA, 2002.

[14] R. Jeewon, S. Y. Q. Yeung, and K. D. Hyde, "A novel phylogenetic group within Thozetella (Chaetosphaeriaceae): a new taxon based on morphology and DNA sequence analyses," Canadian Journal of Microbiology, vol. 55, no. 6, pp. 680-687, 2009.

[15] S. Naeimi, S. A. Khodaparast, M. Javan-Nikkhah, C. Vágvölgyi, and L. Kredics, "Species patterns and phylogenetic relationships of Trichoderma strains in rice fields of Southern Caspian Sea, Iran," Cereal Research Communications, vol. 39, pp. 560-568, 2011.

[16] S. Thongkantha, S. Lumyong, E. H. C. McKenzie, and K. D. Hyde, "Fungal saprobes and pathogens occurring on tissues of Dracaena lourieri and Pandanus spp. in Thailand," Fungal Diversity, vol. 30, pp. 149-169, 2008.

[17] G. E. Harman, C. R. Howell, A. Viterbo, I. Chet, and M. Lorito, "Trichoderma species-opportunistic, avirulent plant symbionts," Nature Reviews Microbiology, vol. 2, no. 1, pp. 43-56, 2004.

[18] B. A. Bailey, M. D. Strem, and D. Wood, “Trichoderma species form endophytic associations within Theobroma cacao trichomes," Mycological Research, vol. 113, no. 12, pp. 1365-1376, 2009.

[19] J. M. U’Ren, J. W. Dalling, R. E. Gallery et al., "Diversity and evolutionary origins of fungi associated with seeds of a neotropical pioneer tree: a case study for analysing fungal environmental samples," Mycological Research, vol. 113, no. 4, pp. 432-449, 2009. 
[20] P. Chaverri, L. A. Castlebury, B. E. Overton, and G. J. Samuels, "Hypocrea/Trichoderma: species with conidiophore elongations and green conidia," Mycologia, vol. 95, no. 6, pp. 1100-1140, 2003.

[21] J. P. Breen, "Acremonium endophyte interactions with enhanced plant resistance to insects," Annual Review of Entomology, vol. 39, pp. 401-423, 1994.

[22] A. E. Glenn, C. W. Bacon, R. Price, and R. T. Hanlin, "Molecular phylogeny of Acremonium and its taxonomic implications," Mycologia, vol. 88, no. 3, pp. 369-383, 1996.

[23] M. Prabakaran, S. Merinal, and A. Panneerselvam, "Investigation of phylloplane mycoflora from some medicinal plants," European Journal of Experimental Biology, vol. 1, no. 2, pp. 219225, 2011.

[24] G. Perrone, G. Stea, F. Epifani, J. Varga, J. C. Frisvad, and R. A. Samson, "Aspergillus niger contains the cryptic phylogenetic species A. awamori," Fungal Biology, vol. 115, no. 11, pp. 1138$1150,2011$.

[25] F. E. Vega, F. Posada, S. W. Peterson, T. J. Gianfagna, and F. Chaves, "Penicillium species endophytic in coffee plants and ochratoxin A production," Mycologia, vol. 98, no. 1, pp. 31-42, 2006.

[26] J. Houbraken, J. C. Frisvad, and R. A. Samson, "Taxonomy of Penicillium section Citrina," Studies in Mycology, vol. 70, no. 1, pp. 153-138, 2011.

[27] L. Chen, W. Liu, X. Hu, K. Huang, J. L. Wu, and Q. Q. Zhang, "Citrinin derivatives from the marine-derived fungus Penicillium citrinum," Chemical and Pharmaceutical Bulletin, vol. 59, no. 4, pp. 515-517, 2011.

[28] F. Posada, M. C. Aime, S. W. Peterson, S. A. Rehner, and F. E. Vega, "Inoculation of coffee plants with the fungal entomopathogen Beauveria bassiana (Ascomycota: Hypocreales)," Mycological Research, vol. 111, no. 6, pp. 748-757, 2007.

[29] A. Garibaldi, P. Martini, L. Repetto et al., "First report of Fusarium oxysporum causing wilt on Iceland poppy Papaver nudicaule in Italy," Plant Disease, vol. 96, article 1823, no. 12, 2012.

[30] J. G. Wei, T. Xu, L. D. Guo, A. R. Liu, Y. Zhang, and X. H. Pan, "Endophytic Pestalotiopsis species associated with plants of Podocarpaceae, Theaceae and Taxaceae in southern China," Fungal Diversity, vol. 24, pp. 55-74, 2007.

[31] R. Gazis and P. Chaverri, "Diversity of fungal endophytes in leaves and stems of wild rubber trees (Hevea brasiliensis) in Peru," Fungal Ecology, vol. 3, no. 3, pp. 240-254, 2010.

[32] R. Jeewon, E. C. Y. Liew, and K. D. Hyde, "Phylogenetic relationships of Pestalotiopsis and allied genera inferred from ribosomal DNA sequences and morphological characters," Molecular Phylogenetics and Evolution, vol. 25, no. 3, pp. 378-392, 2002.

[33] R. Jeewon, E. C. Y. Liew, J. A. Simpson, I. J. Hodgkiss, and K. D. Hyde, "Phylogenetic significance of morphological characters in the taxonomy of Pestalotiopsis species," Molecular Phylogenetics and Evolution, vol. 27, no. 3, pp. 372-383, 2003.

[34] R. Jeewon, E. C. Y. Liew, and K. D. Hyde, "Molecular systematics of the Amphisphaeriaceae based on cladistic analyses of partial LSU rDNA gene sequences," Mycological Research, vol. 107, no. 12, pp. 1392-1402, 2003.

[35] T. R. Nag Rag, Coelomycetous Anamorphs with Appendage Bearing Conidia, Mycologue Publications, Waterloo, Ontaria, Canada, 1993.

[36] W. Y. Huang, Y. Z. Cai, S. Surveswaran, K. D. Hyde, H. Corke, and M. Sun, "Molecular phylogenetic identification of endophytic fungi isolated from three Artemisia species," Fungal Diversity, vol. 36, pp. 69-88, 2009.
[37] N. F. Wulandari, C. To-anun, K. D. Hyde et al., "Phyllosticta citriasiana sp. nov., the cause of Citrus tan spot of Citrus maxima in Asia," Fungal Diversity, vol. 34, pp. 23-39, 2009.

[38] C. Glienke, O. L. Pereira, D. Stringari et al., "Endophytic and pathogenic Phyllosticta species, with reference to those associated with Citrus Black Spot," Persoonia, vol. 26, pp. 47-56, 2011.

[39] A. K. Pandey, M. S. Reddy, and T. S. Suryanarayanan, "ITSRFLP and ITS sequence analysis of a foliar endophytic Phyllosticta from different tropical trees," Mycological Research, vol. 107, no. 4, pp. 439-444, 2003.

[40] P. W. Crous, B. Slippers, M. J. Wingfield et al., "Phylogenetic lineages in the Botryosphaeriaceae," Studies in Mycology, vol. 55, pp. 235-253, 2006.

[41] J. Santamaría and P. Bayman, "Fungal epiphytes and endophytes of coffee leaves (Coffea arabica)," Microbial Ecology, vol. 50, no. 1, pp. 1-8, 2005.

[42] M. T. Hoffman and A. E. Arnold, "Geographic locality and host identity shape fungal endophyte communities in cupressaceous trees," Mycological Research, vol. 112, no. 3, pp. 331-344, 2008.

[43] A. Spagnolo, G. Marchi, F. Peduto, A. J. L. Phillips, and G. Surico, "Detection of Botryosphaeriaceae species within grapevine woody tissues by nested PCR, with particular emphasis on the Neofusicoccum parvum/N. ribis complex," European Journal of Plant Pathology, vol. 129, no. 3, pp. 485-500, 2011. 

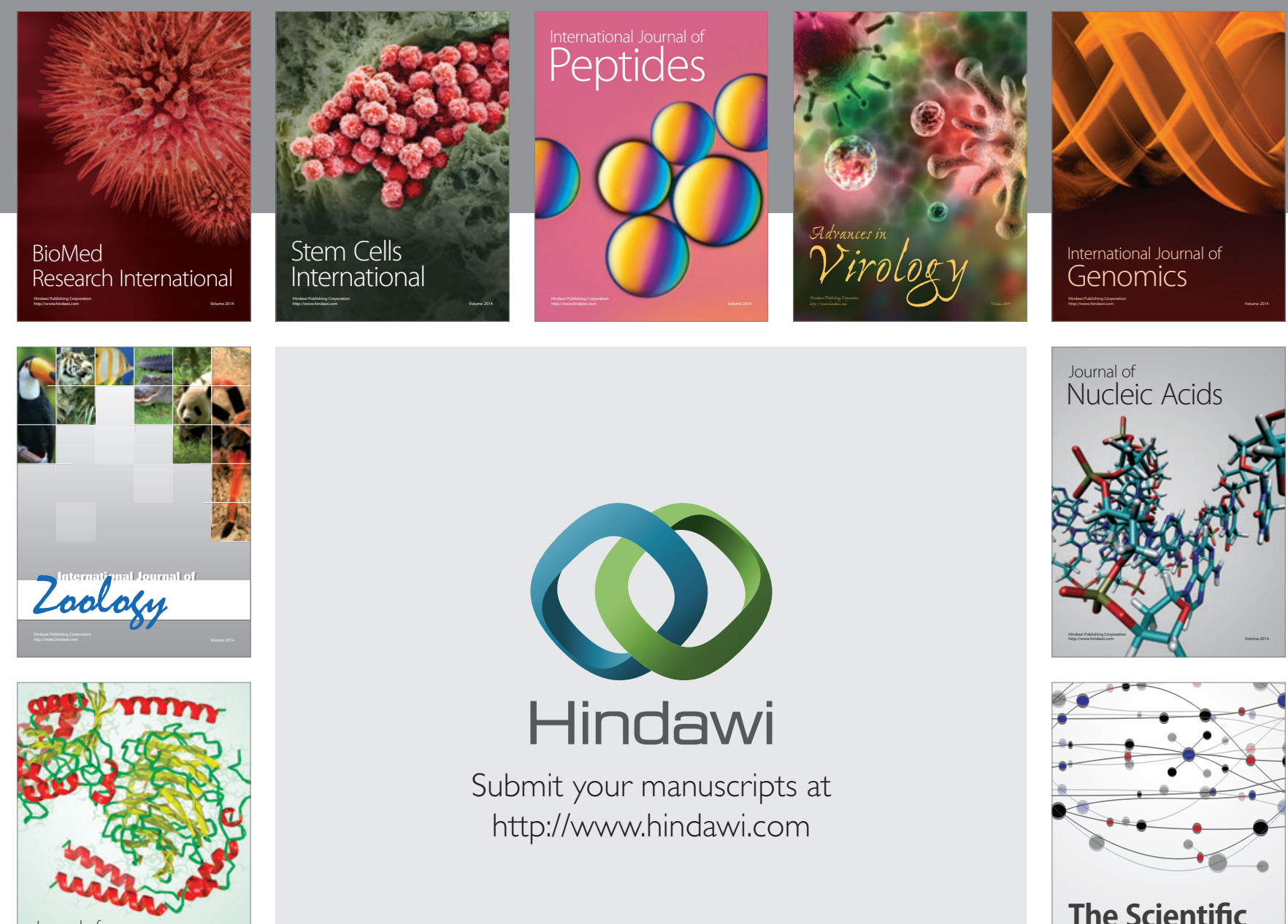

Submit your manuscripts at

http://www.hindawi.com

Journal of
Signal Transduction
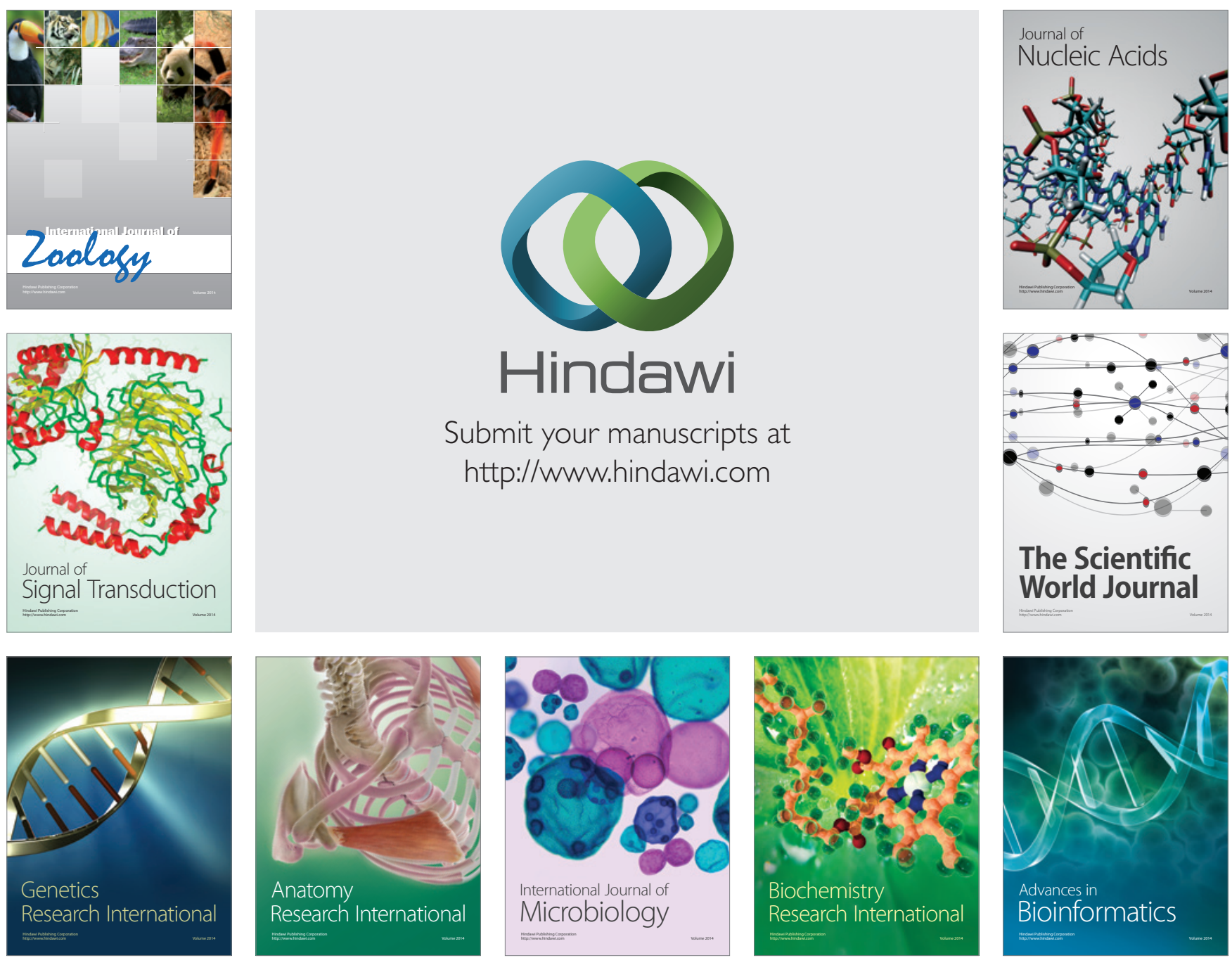

The Scientific World Journal
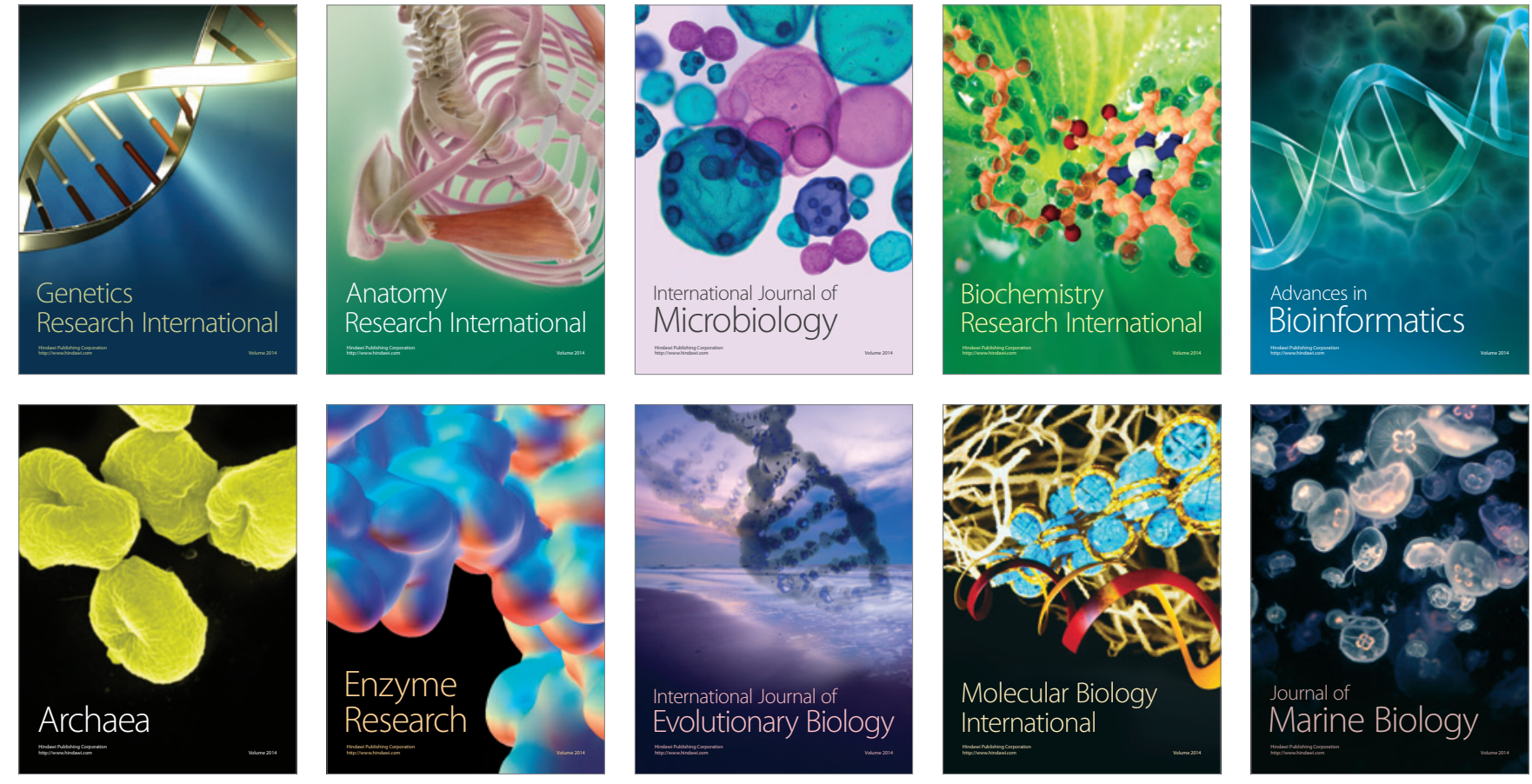